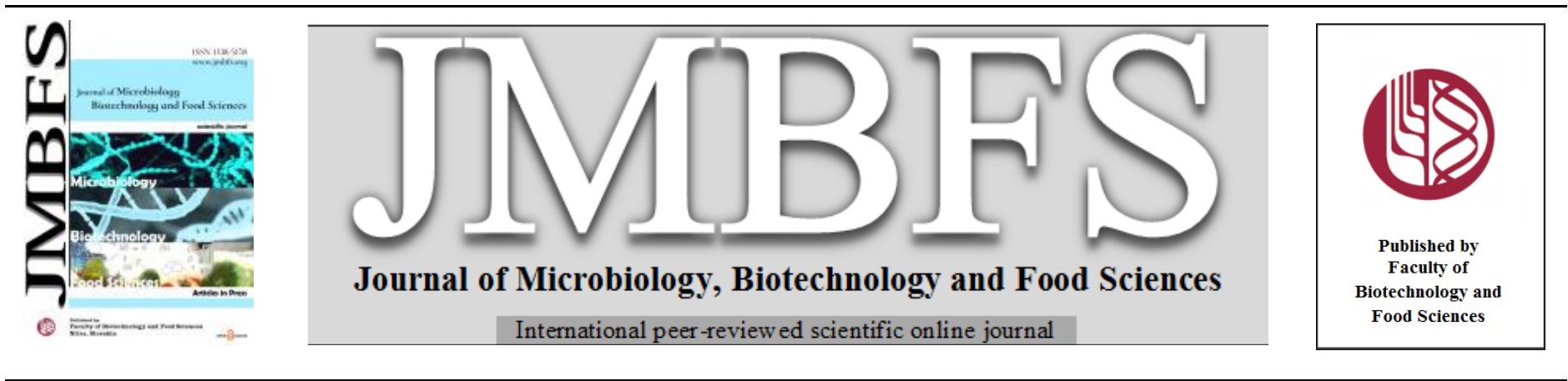

\title{
DEVELOPMENT OF A CALCIUM-FORTIFIED DRINK BASED ON KEFIR, EGGSHELL, CITRIC FRUITS, AND TAP WATER
}

\author{
Maria Eugenia Chulibert*1,2, Cecilia Casabonne ${ }^{4}$, Silvana Sandra Ramadán ${ }^{5}$, and Alfredo Rigalli ${ }^{1,2,3}$ \\ Address(es): María Eugenia Chulibert, \\ ${ }^{1}$ Rosario National University, Faculty of Medicine, Bone Biology Lab, Santa Fe 3100, 2000 Rosario, Santa Fe, Argentina. Number celphone: $341-6808629$. \\ ${ }^{2}$ National Council of Scientific and Technical Research (CONICET), Buenos Aires, Argentina. \\ ${ }^{3}$ Rosario National University, Research Council, 2000 Rosario, Santa Fe, Argentina. \\ ${ }^{4}$ Rosario National University, Faculty of Biochemistry and Pharmacy, Bacteriology Area, Suipacha 531, 2000 Rosario, Santa Fe, Argentina. \\ ${ }^{5}$ Rosario National University, Faculty of Biochemistry and Pharmacy, The Mycology Reference Center, Suipacha 531, 2000 Rosario, Santa Fe, Argentina.
}

*Corresponding author: maruchulibert@gmail.com

https://doi.org/10.55251/jmbfs.4418

\section{ARTICLE INFO}

Received 1.3.2021

Revised 31. 1. 2022

Accepted 8. 2. 2022

Published 1. 6. 2022

Regular article

open $\partial_{\text {ACCESS }}$

\begin{abstract}
Calcium is an essential and critical component of human health. However, most people do not cover daily calcium recommendations. Therefore, a calcium-based drink, called BEVERAGE, is developed in order to offer an alternative source of this mineral to the population. A combination of kefir, eggshell, citric fruits, and tap water were investigated. Orange was selected because it provides the highest amount of carbohydrates for fermentation, and it is accessible to the population. The proportion of components that produce the highest concentration of calcium in the BEVERAGE was with $10 \mathrm{~g}$ of kefir, $6 \mathrm{~g}$ of eggshell, $200 \mathrm{ml}$ of orange juice, and $800 \mathrm{ml}$ of tap water, 20 ${ }^{\circ} \mathrm{C}$, and $72 \mathrm{~h}$ of incubation. With these conditions, the BEVERAGE was fortified with $600 \mathrm{mg}$ calcium/liter. In addition, the intestinal absorption of calcium was evaluated through an ex vivo model of the everted small intestinal sacs, proving to be higher than the control solutions (water $+\mathrm{CaCl}_{2}$, juice $+\mathrm{CaCl}_{2}$ ). This study provides a methodology to prepare at home a beverage that could contribute to increase daily calcium intake.
\end{abstract}

Keywords: calcium deficiency, eggshell, kefir grains, calcium supplementation

\section{INTRODUCTION}

Calcium $(\mathrm{Ca})$ is an essential and critical component for human health. This element takes part in various biological processes, such as nerve conduction, muscle contraction, bone structure, signal transduction, regulation of hormonal secretion, and vascular activities (Li et al., 2018). About ninety-nine percent of the calcium contained in the human body is stored in the skeleton under the form of hydroxyapatite and other calcium salts. Calcium intake is of utmost importance during the early stages of life, since the increase in bone mass takes place up to the age of 30 years old (Wlodarek et al., 2014).

Although calcium is abundant in foods, its bioavailability is very different among them. Many plant-based foods have low bioavailability of calcium, especially due to the presence of oxalic acid (Etcheverry et al., 2012). Conversely, dairy products are excellent sources of calcium and the bioavailability is high, favoured by the presence of carbohydrates (Cámara-Martos \& Amaro-López, 2002), milk proteins (Shimizu, 2004) and peptides generated from the digestion of proteins of milk (Liu et al., 2018). The most important source of calcium is dairy products, constituting more than $60 \%$ of daily intake (Gonnelli et al., 2009). The intake of calcium from other sources can reach a maximum of $250 \mathrm{mg} \mathrm{Ca} /$ day. For these reasons, the consumption of dairy products is recommended for the adequate development of bone mass (Reid et al., 2014). In the prevention of osteoporosis, besides the consumption of dairy products, calcium supplements are available to compensate for the deficiency in the intake of this micronutrient (Heaney, 2000). The Recommended Dietary Allowance (RDA) of calcium set by Institute of Medicine for adult people is $1000 \mathrm{mg}$. In general, a minority of individuals reaches the mentioned daily requirement (Greer et al., 2006). For example, lactose intolerance is an illness caused by a low activity of duodenal lactase and this deficit leads people to reduce the intake of dairy products (Facioni $\boldsymbol{e t}$ al., 2020), often by self-diagnosis of the disease (Nicklas et al., 2011). In addition, the number of consumers following a vegan diet has markedly increased, and their influence in the food sector will likely continue to grow (Rosenfeld, 2018). Concerns like dietary fat, cholesterol, and other related allergies, among some individuals, have led to switch their preferences from dairy to non-dairy products. Consequently, these people are at risk of low calcium intake. Thus, the difference between recommended and actual calcium intake compel the manufacturers to market an increasing number and variety of calcium-fortified products (Konar et al., 2015). Food fortification is one of the most effective strategies to improve nutrient intake. Fortification has been used in high-income countries for more than 80 years.
However, despite this vast experience, fortified foods are not always accessible to low socioeconomic groups (Allen et al., 2006). However, outside of dairy and these beverages, there are few calcium-rich foods for non-dairy consumers, most of which contain less calcium per serving than dairy products and dairy substitutes (Hodges et al., 2019).

The composition of the chicken eggshell and its use as a low-cost source of calcium has been evaluated, showing that $1 \mathrm{~g}$ of chicken eggshell could provide $50 \%$ of an adult's daily requirement (Brun et al., 2013). Because it is possible to eliminate potential pathogens on eggshells, eggshell consumption as a calcium supplement can be considered safe and could play a role in relieving calcium deficiency (Bartter et al., 2018).

The chicken eggshell has been used to fortify milk with calcium simultaneously with the use of microorganisms (kefir). The fermentative activity of kefir produces a decrease in $\mathrm{pH}$, which favours the dissolution of the eggshell, which is composed mainly of calcium carbonate (Fina et al., 2016). On the other hand, water kefir is a fermented and home-produced beverage made by adding kefir grain to sugar solution in water and incubating this mixture at $20-25^{\circ} \mathrm{C}$ for at least $12 \mathrm{~h}$, and then separating of kefir grain to other production. Fresh or dried fruit slices can be added for flavour and removed at the end of the fermentation period (Muneer Alsayadi et al., 2016).

Given the importance of calcium for the organism and knowing the low number of individuals to reach the RDA of calcium for different reasons, the objectives of our study were to develop a high calcium content drink based on kefir, eggshell, citric fruits, and tap water, and we refer to this preparation as the "BEVERAGE". It will be useful if the calcium is absorbed at the intestinal level. For this reason, the following objective was to evaluate the intestinal calcium absorption in rats

\section{MATERIAL AND METHODS}

\section{Fruit selection}

Juices from citrus fruits were tested, due to easy handling for its extraction, its natural acidity, and its accessibility. To select fruit for fermentation, juices from tangerine, orange, grapefruit, and lemon were obtained and $\mathrm{pH}$, titratable acidity, conductivity, and carbohydrates (glucose and fructose) content were measured. 


\section{Optimization of BEVERAGE preparation}

The incorporation of calcium to the BEVERAGE was obtained with kefir, eggshell, orange juice, and tap water. Kefir was obtained from a commercial brand of Argentina (Prama ${ }^{\circledR}$, Argentina). Dry eggshells were mechanically processed using a mixer mill (Retsch GmbH, MM200, Haan, Germany) for $20 \mathrm{~min}$ at a frequency of $30 \mathrm{~s}-1$ as a standard method. Then the chicken eggshell powder was sterilized in an automatic sterilizer autoclave (Microclave SL 9000, Buenos Aires, Argentina) for $15 \mathrm{~min}$ at $134{ }^{\circ} \mathrm{C}$ and $30 \mathrm{psi}$ (according to manufacturer's instructions) before adding to the BEVERAGE.

Different levels of factors were tested to reach the greatest dissolution of the $\mathrm{CaCO}_{3}$ from the eggshell. A factorial design was carried out using the following factors and their respective levels: eggshell quantity $(0,0.5,2.5,4$ and $6 \mathrm{~g})$, time $(0,24,48$ and $72 \mathrm{~h})$ and temperature $\left(8,12\right.$ and $\left.20^{\circ} \mathrm{C}\right)$. All samples had $10 \mathrm{~g}$ of kefir, $200 \mathrm{ml}$ of orange juice and $800 \mathrm{ml}$ of tap water. Since it is a full factoria design, the number of experimental units arises from the product of the number of levels of each factor. Calcium concentration of tap water mean $=15.4 \mathrm{mg} / \mathrm{L}$, $\mathrm{SD}=5.3, \mathrm{n}=30$. At the end of the fermentation process, calcium and $\mathrm{pH}$ were measured.

\section{Intestinal calcium absorption}

The experiments that are described from here were carried out with the following composition: kefir $10 \mathrm{~g}$, eggshell $6 \mathrm{~g}$, orange juice $200 \mathrm{ml}$, tap water to reach 1000 $\mathrm{ml}$, fermented at $20^{\circ} \mathrm{C}$ for $72 \mathrm{~h}$. See the below results that support this decision. The intestinal calcium absorption is a process that mainly occurs in the small intestine (Diaz De Barboza et al., 2015). Calcium intestinal absorption was evaluated through an ex vivo model of the everted small intestinal sacs (Brun et al., 2009). Experiments were carried out in female Sprague Dawley rats of 180 $220 \mathrm{~g}$ of body weight. Rats, provided by the School of Medicine, Rosario National University (Argentina), were fed with balanced food for rodents (Gepsa, Argentina) and water ad libitum. Before the experiments, rats were kept in a temperature-controlled environment of $23-25^{\circ} \mathrm{C}$, with a $12 \mathrm{~h}-12 \mathrm{~h}$ light-dark cycle and filtered airflow at scheduled time interval. All the experiments were conducted in accordance with international guidelines for animal care (Olfert et al., 1993) and this work has been approved by the Ethical Committee of the School of Medicine, Rosario National University (number of resolution: 2162/2017).

Preparation of everted small intestinal sacs: after euthanasia by $\mathrm{CO}_{2}$ inhalation, the small intestine was removed from 4 rats and everted, rinsed with $9 \mathrm{~g} / \mathrm{L} \mathrm{NaC}$ solution, and divided into segments of similar size. The serous surfaces of the everted small intestinal sacs were exposed for 30 minutes to $0.5 \mathrm{ml}$ of the following solution, which is called internal solution: $1 \mathrm{mmol} / \mathrm{L}$ Tris, $1 \mathrm{mmol} / \mathrm{L} \mathrm{MgCl}_{2}, 160$ $\mathrm{mmol} / \mathrm{L}$ glucose, $100 \mathrm{mmol} / \mathrm{L}$ beta-glycerophosphate, and $\mathrm{pH}$ 9. This solution does not contain calcium, and the final concentration of calcium is used to calculate calcium absorption.

The mucous surfaces were exposed to different solutions:

- BEVERAGE ( $\mathrm{n}=14$ sacs), prepared as stated before.

- Water+ $\mathrm{CaCl}_{2}$ ( $\mathrm{n}=14$ sacs), $\mathrm{CaCl}_{2}$

- Juice+ $\mathrm{CaCl}_{2}$ ( $\mathrm{n}=14$ sacs), orange juice and $\mathrm{CaCl}_{2}$.

Analytical grade calcium chloride was used as a control because it has a high bioavailability ( $\geq 90 \%$ ), it is soluble in water and neutral effect on taste and colour of the product (Tiwari et al., 2018).

All solutions were prepared and were adjusted to have the same concentration (600 $\mathrm{mg} \mathrm{Ca} / \mathrm{L})$.

Sacs were randomly assigned to the mention solutions. Sacs of each treatment were placed in a volume of mucous solution, yielding a mucous/serous ratio of approximately 10 , so that the concentration of calcium in the mucous solution remains constant throughout the experiment. The experiments were carried out at $37^{\circ} \mathrm{C}$ for 30 minutes and samples from the serous compartment were obtained at the end of the incubation period. The rate of calcium absorption $(\mu \mathrm{g} \mathrm{Ca} / \mathrm{min})$ was determined with the serous volume, calcium concentration in the serous compartment, and the duration of the experiment.

\section{Chemical measurements}

Chemical measurements were carried out following standard operating protocols The measurements were carried out on duplicates under strict quality control. The value of a measurement was rejected when the coefficient of variation exceeded $10 \%$. Simultaneously, quality control solutions of known concentration were processed, if the standard deviation units were outside the range $[-2,2]$, the measurement of the entire batch of samples was repeated. Each sample was identified with an alphanumeric code so that the operator did not know the origin of the sample and thus avoid bias in the measurement.

Calcium concentration was measured by atomic absorption spectrometry (Arolab MK II, Buenos Aires, Argentina). The samples were diluted in a solution of strontium chloride $2 \%$ to remove interference by calcium complexing anions. Two $\mathrm{ml}$ of the sample was volatilized in acetylene-oxygen (1.5:2) flame and the absorbance at $424 \mathrm{~nm}$ from a calcium lamp was measured. Standard solutions of calcium $(1-100 \mathrm{ug} / \mathrm{ml})$ were processed simultaneously to obtain a calibration curve. $\mathrm{pH}$ was measured immediately after the sample was extracted using a Methrom $632 \mathrm{pH}$ meter calibrated for the range of 4-7.

Electrical conductivity was measured with a Hanna 430 conductivity meter.

Titratable acidity measurement was performed by titration of a volume of $2 \mathrm{ml}$ of each juice fruit with $\mathrm{NaOH} 0.1 \mathrm{~mol} / \mathrm{L}$ and was expressed as the milliequivalents of $\mathrm{NaOH}$ spent per liter of the juice to reach $\mathrm{pH}=7$.

Glucose and fructose concentrations were measured after acid hydrolysis with $\mathrm{HCl}$ $36 \% \mathrm{~W} / \mathrm{W}$. The process was performed with ratio juice/ $\mathrm{HCl}: 100 / 5$. Glucose concentration $(\mathrm{g} / \mathrm{L})$ measurement was performed spectrophotometrically with a commercial kit based on glucose oxidase (Wiener Lab, Rosario, Argentina) at 505 $\mathrm{nm}$. Fructose concentration $(\mathrm{g} / \mathrm{L})$ measurement was performed at $406 \mathrm{~nm}$ after treatment of samples with $30 \% \mathrm{HCl}$ and $0.1 \%$ resorcinol at $80{ }^{\circ} \mathrm{C}$ (Roe, 1934).

\section{Statistical analyse}

The data obtained from the experiments were analysed with the $\mathrm{R}$ program, version 3.2.2. The factorial design was analysed with ANOVA and linear models, ruling out the interaction between the intermediate factors. The principal component analysis was performed with the FactoMineR package for R 3.2.2. When the values of more than two treatments were compared, ANOVA was used for two criteria and the differences between the groups were analysed with the LSD.test of the Agricolae R package, with Bonferroni's correction.

\section{RESULTS AND DISCUSSION}

\section{Fruit selection}

Orange juice was selected for the following experiments as it provides the highes amount of carbohydrates for fermentation although $\mathrm{pH}$ is not the lowest and titrable acidity is not the highest. Besides, oranges are available in all seasons of the year, they are accessible to the population and its juice is easily obtained. Tab 1 shows the values of $\mathrm{pH}$, conductivity, titrable acidity, and carbohydrates concentration measured in citric fruits.

Table 1 Measured variables in citrus fruits

\begin{tabular}{lcccc}
\hline Measurements & Lemon & Grapefruit & Orange & Tangerine \\
\hline $\mathrm{pH}$ & $2.27 \pm 0.19^{\mathrm{c}}$ & $3.09 \pm 0.38^{\mathrm{b}}$ & $3.66 \pm 0.29^{\mathrm{a}}$ & $3.89 \pm 0.36^{\mathrm{a}}$ \\
$\begin{array}{l}\text { Conductivity } \\
(\mathrm{mS} / \mathrm{cm})\end{array}$ & $4.10 \pm 1.03^{\mathrm{a}}$ & $2.91 \pm 0.27^{\mathrm{b}}$ & $2.87 \pm 0.76^{\mathrm{b}}$ & $2.39 \pm 0.14^{\mathrm{b}}$ \\
$\begin{array}{l}\text { Titratable acidity } \\
(\mathrm{mEq} / \mathrm{L})\end{array}$ & $555.22 \pm 275.62^{\mathrm{a}}$ & $220.24 \pm 58.74^{\mathrm{b}}$ & $109.48 \pm 43.61^{\mathrm{c}}$ & $90.55 \pm 39.66^{\mathrm{c}}$ \\
$\begin{array}{l}\text { Carbohydrates } \\
(\mathrm{g} / \mathrm{L})\end{array}$ & $42.76 \pm 21.84^{\mathrm{b}}$ & $80.51 \pm 29.58^{\mathrm{b}}$ & $148.29 \pm 72.98^{\mathrm{a}}$ & $144.23 \pm 62.91^{\mathrm{ab}}$ \\
\hline $\begin{array}{l}\text { Measured variables expressed as } \text { mean } \pm \text { standard deviation. Different letters } \\
\text { between columns of the same row indicate significant differences between } \\
\text { solutions. ANOVA, LSD test }(p<0.05) \text {. }\end{array}$
\end{tabular}

\section{Optimization of BEVERAGE preparation}

The effect of the different factors (time, temperature, amount of eggshell, amount of kefir) on the calcium concentration of the BEVERAGE was analysed with a factorial design and multiple analyses of variance. Then, the individual effect of each level of the different factors was analysed with the coefficient of a linear model. A previous analysis rejected the interaction between factors. According to the ANOVA, the amounts of eggshell and fermentation time are factors that significantly influence calcium concentration $(\mathrm{p}<0.05)$. The incubation time $72 \mathrm{~h}$ and $6 \mathrm{~g}$ of eggshell contributed the highest calcium content, providing $600 \mathrm{mg} / \mathrm{L}$. The following linear model was used: calcium concentration $=a^{*}$ amount of eggshell $+\mathrm{b} *$ temperature $+\mathrm{c} *$ time + intercept, where $\mathrm{a}, \mathrm{b}$ and $\mathrm{c}$ are coefficients of the model. The model fitted experimental values $\left(R^{2}=0.91, p<0.05\right)$ and the amount of eggshell $(2.5,4$, and $6 \mathrm{~g})$ and the time $(24,48$, and $72 \mathrm{~h})$ are factors that significantly influence calcium concentration $(\mathrm{p}<0.05)$, but not temperature (Tab 2 ). The model assigns coefficient equal to zero for the lowest value of each factor (reference factor). A positive coefficient indicates an increase in calcium concentration compared to the reference level of each other.

The effect of the different time, temperature, and amount of eggshell on calcium concentration was analysed through a linear model and PCA. According to the linear model, the amount of eggshell and the time were factors that significantly influence calcium concentration of BEVERAGE. The temperature has not effect on calcium concentration. According to linear model, the optimal conditions that allow a drink with a greater amount of calcium were: $6 \mathrm{~g}$ of the eggshell with fermentation for $72 \mathrm{~h}$, providing $600 \mathrm{mg} \mathrm{Ca} / \mathrm{L}$. This concentration was achieved with a small amount of carbohydrates available for fermentation. This suggests that the higher the amount of carbohydrates, the higher the calcium concentration is likely to be achieved. More studies are needed to test this hypothesis. 
Calcium concentration and $\mathrm{pH}$ had a significantly correlation $\left(\mathrm{R}^{2}=0.94, \mathrm{p}<0.05\right)$. As an attempt to find the relationship between calcium concentration and $\mathrm{pH}$ in the presence of other variables, Principal Components Analysis (PCA) was used. The analysis of data with PCA analysis confirms those found with a linear model. PCA analysis can be found as Complementary analysis.

Table 2 Coefficient of the linear model proposed for each factor

\begin{tabular}{lll}
\hline Factor levels & Coefficients $(\mathrm{mg} / \mathrm{L})$ & P-value \\
\hline Eggshell: 0 & 0 & \\
Eggshell: $0.5 \mathrm{~g}$ & 56.16 & 0.001867 \\
Eggshell: $2.5 \mathrm{~g}$ & 238.95 & $<2 \mathrm{e}-16$ \\
Eggshell: $4 \mathrm{~g}$ & 355.79 & $<2 \mathrm{e}-16$ \\
Eggshell: $6 \mathrm{~g}$ & 463.96 & $<2 \mathrm{e}-16$ \\
Temperature: $8{ }^{\circ} \mathrm{C}$ & 0 & 0.387171 \\
Temperature: $12^{\circ} \mathrm{C}$ & 13.89 & 0.317904 \\
Temperature: $20^{\circ} \mathrm{C}$ & 16.06 & \\
Time: $0 \mathrm{~h}$ & 0 & 0.017572 \\
Time: $24 \mathrm{~h}$ & 43.87 & $1.89 \mathrm{e}-05$ \\
Time: $48 \mathrm{~h}$ & 82.80 & $4.25 \mathrm{e}-09$ \\
\hline Time: $72 \mathrm{~h}$ & 120.97 & \\
\hline
\end{tabular}

$P$-value $<0.01$ indicates significant difference in calcium concentration from the reference level of the factor.

Although plant-based food contains inhibitor factors to calcium absorption, microbial fermentation is one of the actual methods to obtain bioactive nutrients During the fermentation process, microorganisms transform complex substances into small ones that improve the nutritional quality of foods (Xiang et al., 2019).

\section{Intestinal calcium absorption}

The calcium absorption rate of the BEVERAGE was evaluated in everted small intestinal sac model. The BEVERAGE had a higher absorption rate than the juice $+\mathrm{CaCl}_{2}$ and even than the water $+\mathrm{CaCl}_{2}$ solution, ANOVA, LSD.test, $\mathrm{p}<0.05$ (Tab 3).

Table 3 Calcium absorption rate of ex vivo small intestinal everted sac after $30 \mathrm{~min}$ incubation with different mucous solutions

\begin{tabular}{lc}
\hline Mucous solutions & Calcium absorption rat \\
\hline water+CaCl & $(\mathrm{n}=14)$ \\
juice $+\mathrm{CaCl}_{2}(\mathrm{n}=14)$ & $20.5 \pm 2.3^{\mathrm{a}}$ \\
BEVERAGE $(\mathrm{n}=14)$ & $9.2 \pm 4.1^{\mathrm{b}}$
\end{tabular}

Results are expressed as mean \pm standard deviation. Different superscript letter indicates significant differences. One way ANOVA, LSD test $(p<0.05)$.

Studying calcium absorption through an ex vivo model contributes to better contro of the experiments and a greater number of experimental units. Furthermore, the everted small intestinal sac technique allows the reduction of animals because control animals from other experiments can be used. Instead, the isolated intestinal model implies the use of 1 live animals per experiment. However, with the mode used in this paper, it is not possible to evaluate the calcium absorption taking into account the integrity of the system.

Mineral waters rich in calcium have been reported to be a valuable and bioavailable source of $\mathrm{Ca}$ with beneficial effects measured through biomarkers and bone densitometric parameters (Vannucci et al., 2018). Also, intestinal calcium absorption from the BEVERAGE was significantly higher than the juice $+\mathrm{CaCl}_{2}$ This difference could be explained because of the presence of citrate and other substances present in the juice, which has a complex action with calcium. Kefir could metabolize these acids, avoiding the formation of calcium with low absorption. However, this hypothesis should be verified.

\section{Complementary analysis}

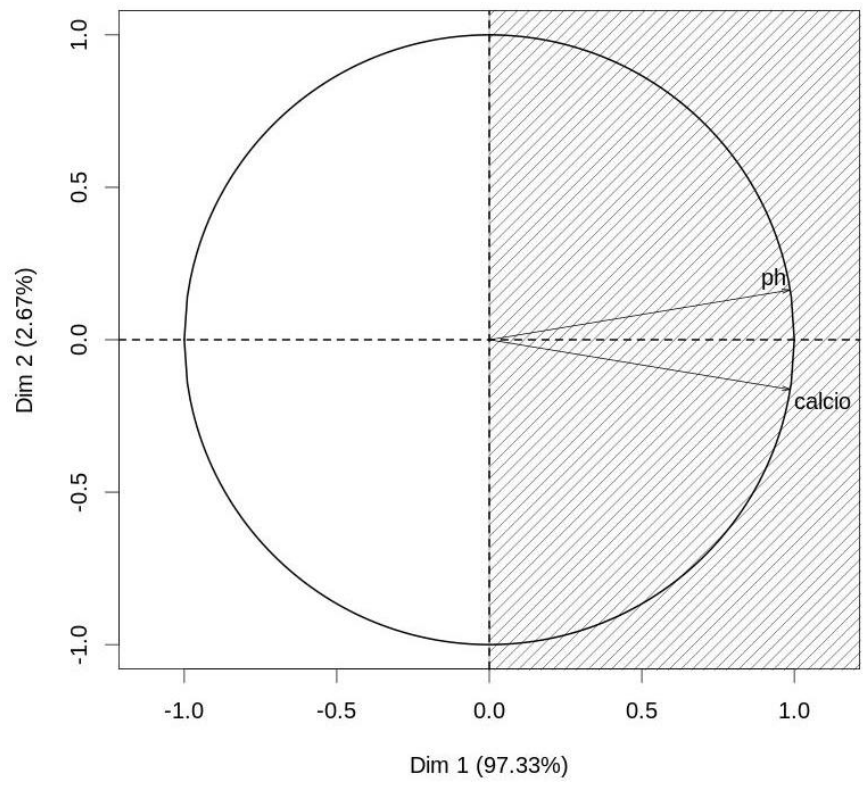

Figure 1 Principal Component Analysis (PCA).

PCA describes the effect of time, $\mathrm{pH}$, temperature, and the amount of eggshell on the concentration of $\mathrm{Ca}$. Figure 1 shows map variables of PCA indicating that $\mathrm{pH}$ and calcium concentration are positively correlated, as indicated by the direction of vectors that represent the variables. The map also indicates that the samples with higher $\mathrm{pH}$ and calcium concentration are preferentially placed in the right halfplane, while samples with lower $\mathrm{pH}$ and calcium concentration will be most probably found in the left half-plane. In addition, an analysis of the ellipses was carried out, which shows that longer incubation time and quantity of eggshell allow higher values of calcium concentration and $\mathrm{pH}$.

Figure 2 displays the samples and the 0.95 confidence ellipses of different incubation time. The higher the incubation time, the higher the $\mathrm{pH}$ and calcium concentration. Ellipses display the position of samples with different incubation times. Although there is no great differences, the ellipses indicate that the higher the incubation time, the highest the calcium concentration. Figure 3 displays the effect of temperature on calcium and $\mathrm{pH}$. The results indicate that the temperature is the principal factor to control in the preparation process of the BEVERAGE. Figure 4 displays samples and 0.95 confidence ellipses for a different amount of eggshell, showing higher $\mathrm{pH}$ and calcium concentration as the amount of eggshell increases.

Individuals factor map (PCA)

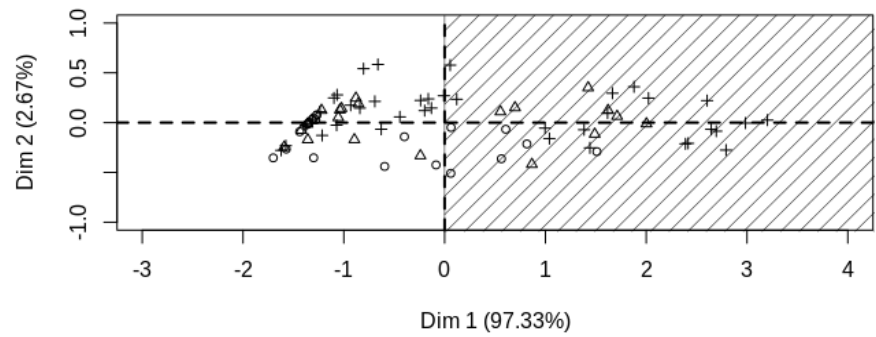

Individuals factor map (PCA)

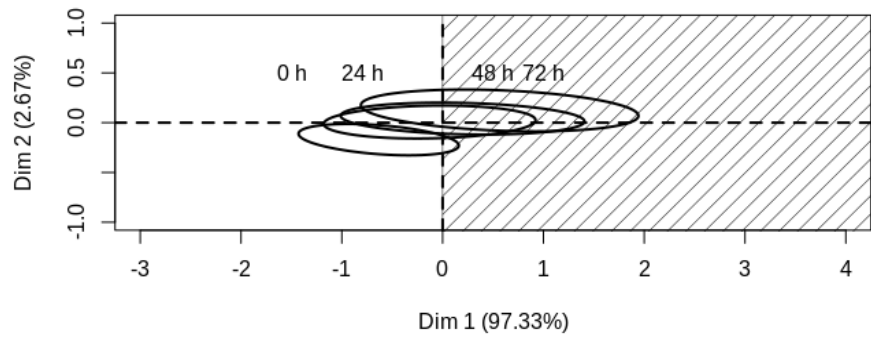

Figure 2 Upper panel. Incubation time. $\circ: 0 \mathrm{~h}, \Delta: 24 \mathrm{~h},+: 48 \mathrm{~h}, \diamond: 72 \mathrm{~h}$. Lower panel: 95 confidence ellipses for different amount of eggshell. Shadow right area has high calcium concentration and high $\mathrm{pH}$ values. 


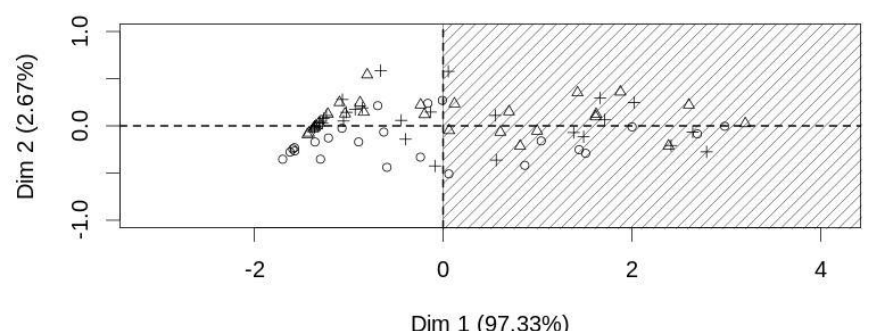

$\operatorname{Dim} 1(97.33 \%)$

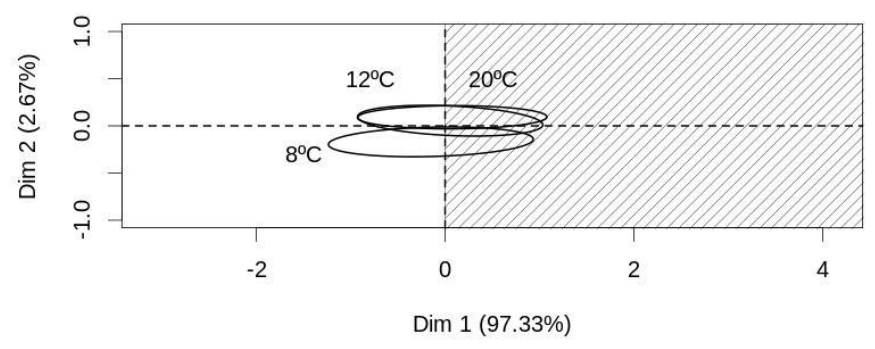

Figure 3 Upper panel. Incubation temperature. $\circ: 8^{\circ} \mathrm{C}, \Delta: 12{ }^{\circ} \mathrm{C},+: 20^{\circ} \mathrm{C}$. Lower panel: 95 confidence ellipses for different amount of eggshell. Shadow right area has high calcium concentration and high $\mathrm{pH}$ values.
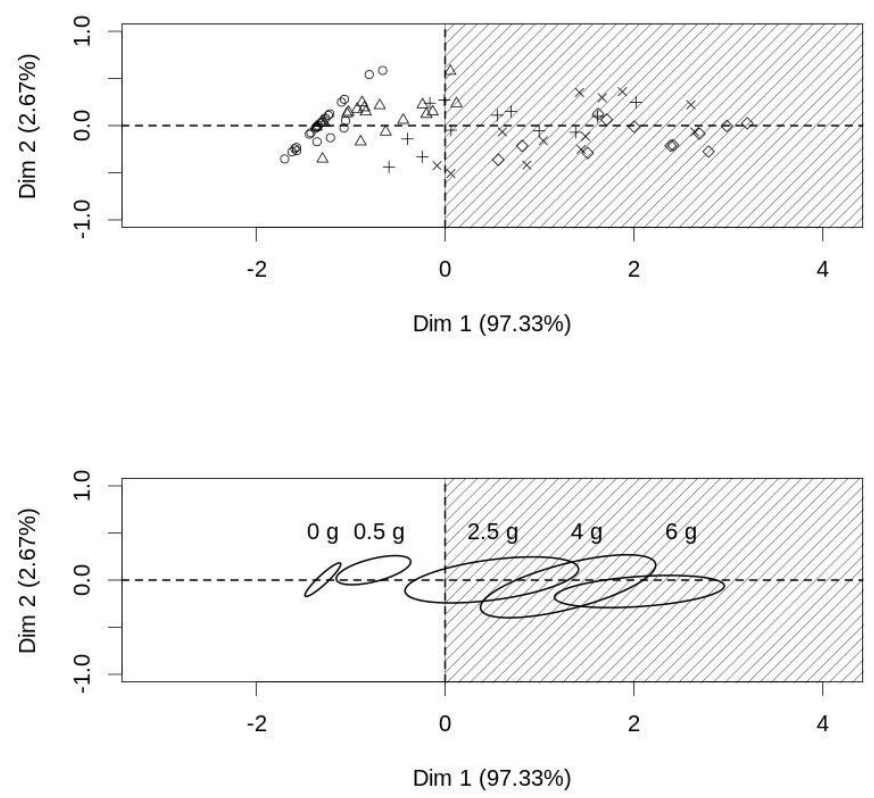

Figure 4 Upper panel. Amount of eggshell. ॰: $0 \mathrm{~g}, \Delta: 0.5 \mathrm{~g},+: 2.5 \mathrm{~g}, \diamond: 4 \mathrm{~g}, \mathrm{x}: 6 \mathrm{~g}$. Lower panel: 95 confidence ellipses for different amount of eggshell. Shadow right area has high calcium concentration and high $\mathrm{pH}$ values.

\section{CONCLUSION}

Although calcium is an essential and critical component for human health, the vast majority of people do not cover the daily recommendations. Dairy products are the most important source of dietary calcium. However, issues related to diseases, cost, or eating habits, do not always consume them. The development of new sources of calcium not derived from milk is important to cover daily calcium requirement. This work developed a calcium-fortified non-dairy drink with kefir, eggshell, citric fruits, and tap water. The effect of these factors on the calcium concentration of the drink, and calcium intestinal absorption were evaluated. The optimal conditions that allow a drink with a greater amount of calcium are: $6 \mathrm{~g}$ of the eggshell with fermentation for $72 \mathrm{~h}$, providing $600 \mathrm{mg} \mathrm{Ca} / \mathrm{L}$. From the experiments carried out, it is concluded that the BEVERAGE contributes to bioavailable calcium. The intestinal absorption of calcium from the BEVERAGE was higher than the control solution.
The results of this job indicate that the BEVERAGE is a safe, practical, and acceptable method to improve dietary calcium intakes. The BEVERAGE has certain characteristics that deserve to be highlighted: high calcium bioavailability, the possibility of home preparation, and use of household waste. Besides, the BEVERAGE does not contain milk, which makes it useful for those people who for various reasons cannot consume dairy products.

Acknowledgments: We thank Patricia Melina Lupión, Mercedes Lombarte, Agustina Del Ponte, and Thiago Andrade for technical assistance.

Financial support: The research was funded by the service department of the Bone Biology Laboratory and the Rosario National University. Salaries of authors were paid by Rosario National University and National Council of Scientific and Technical Research (CONICET).

Conflict of Interest: María Eugenia Chulibert, Cecilia Casabonne, Silvana Sandra Ramadán, and Alfredo Rigalli declare that they have no conflict of interest.

\section{REFERENCES}

Allen, L., De Benoist, B., Dary, O., \& Hurrell, R. (2006). Guidelines on Food Fortification with Micronutrients. WHO; Geneva, Switzerland: file:///tmp/mozilla_maru0/9241594012_eng.pdf

Bartter, J., Diffey, H., Yeung, Y. H., O’Leary, F., Häsler, B., Maulaga, W., \& Alders, R. (2018). Use of chicken eggshell to improve dietary calcium intake in rural sub-Saharan Africa. Maternal \& Child Nutrition, 14, e12649. https://doi.org/10.1111/mcn.12649

Brun, L. R., Brance, M. L., de Candia, L. F., Rigalli, A. (2009). Intestinal Everted Sacs. In V. E. D. L. Alfredo Rigalli (Ed.), Experimental Surgical Models in the Laboratory Rat. https://doi.org/10.1201/9781420093278

Brun, L. R., Lupo, M., Delorenzi, D. A., Di Loreto, V. E., \& Rigalli, A. (2013) Chicken eggshell as suitable calcium source at home. International Journal of Food Sciences and Nutrition, 64(6), 740-743. https://doi.org/10.3109/09637486.2013.787399

Cámara-Martos, F., \& Amaro-López, M. A. (2002). Influence of dietary factors on calcium bioavailability: A brief review. Biological Trace Element Research, 89(1) 43-52. https://doi.org/10.1385/BTER:89:1:43

Diaz De Barboza, G., Guizzardi, S., \& Tolosa De Talamoni, N. (2015). Molecular aspects of intestinal calcium absorption. World Journal of Gastroenterology, 21(23), 7142-7154. https://doi.org/10.3748/wjg.v21.i23.7142

Etcheverry, P., Grusak, M. A., \& Fleige, L. E. (2012). Application of in vitro bioaccessibility and bioavailability methods for calcium, carotenoids, folate, iron, magnesium, polyphenols, zinc, and vitamins B 6, B 12, D, and E. In Frontiers in Physiology: Vol. 3 AUG (p. 317). Frontiers. https://doi.org/10.3389/fphys.2012.00317

Facioni, M. S., Raspini, B., Pivari, F., Dogliotti, E., Cena, H., \& Cena, H. (2020) Nutritional management of lactose intolerance: The importance of diet and food labelling. In Journal of Translational Medicine (Vol. 18, Issue 1, pp. 1-9). BioMed Central. https://doi.org/10.1186/s12967-020-02429-2

Fina, B. L., Brun, L. R., \& Rigalli, A. (2016). Increase of calcium and reduction of lactose concentration in milk by treatment with kefir grains and eggshell. International Journal of Food Sciences and Nutrition, 67(2), 133-140 https://doi.org/10.3109/09637486.2015.1137888

Gonnelli, S., Rossi, S., Montomoli, M., Caffarelli, C., Cuda, C., Lazzeri, G. Giacchi, M., \& Nuti, R. (2009). Accuracy of different reduced versions of validated food-frequency questionnaire in Italian men and women. Calcified Tissue International, 85(3), 221-227. https://doi.org/10.1007/s00223-009-9264-4

Greer, F. R., Krebs, N. F., Baker, R. D., Bhatia, J. J. S., Heyman, M. B., Lifshitz, F., Blum-Kemelor, D., Boland, M. P., Dietz, W., Hubbard, V. S., Walker, S. J., \& Kanda, P. T. (2006). Optimizing bone health and calcium intakes of infants, children, and adolescents. Pediatrics, 117(2), 578-585. https://doi.org/10.1542/peds.2005-2822

Heaney, R. P. (2000). Calcium, Dairy Products and Osteoporosis. Journal of the American College of Nutrition, 19, 83S-99S https://doi.org/10.1080/07315724.2000.10718088

Hodges, J. K., Cao, S., Cladis, D. P., \& Weaver, C. M. (2019). Lactose intolerance and bone health: The challenge of ensuring adequate calcium intake. In Nutrients (Vol. 11, Issue 4). MDPI AG. https://doi.org/10.3390/nu11040718

Institute of Medicine. (2011). Dietary Reference Intakes for Calcium and Vitamin D. Washington, DC: The National Academies Press. https://doi.org/10.17226/13050

Konar, N., Poyrazoglu, E. S., \& Artik, N. (2015). Influence of calcium fortification on physical and rheological properties of sucrose-free prebiotic milk chocolates containing inulin and maltitol. Journal of Food Science and Technology, 52(4) 2033-2042. https://doi.org/10.1007/s13197-013-1229-y

Li, K., Wang, X. F., Li, D. Y., Chen, Y. C., Zhao, L. J., Liu, X. G., Guo, Y. F., Shen, J., Lin, X., Deng, J., Zhou, R., \& Deng, H. W. (2018). The good, the bad, and the ugly of calcium supplementation: A review of calcium intake on human health. In Clinical Interventions in Aging (Vol. 13, pp. 2443-2452). Dove Medica Press Ltd. https://doi.org/10.2147/CIA.S157523 
Liu, G., Sun, S., Guo, B., Miao, B., Luo, Z., Xia, Z., Ying, D., Liu, F., Guo, B., Tang, J., Cao, Y., \& Miao, J. (2018). Bioactive peptide isolated from casein phosphopeptides promotes calcium uptake: In vitro and in vivo. Food and Function, 9(4), 2251-2260. https://doi.org/10.1039/c7fo01709j

Muneer Alsayadi, M. S., Al jawfi, Y., Belarbi, M., Z Sabri, F. (2016). Antioxidant potency of water kefir. Journal of Microbiology, Biotechnology and Food Sciences, 6, 2444-2447.

Nicklas, T. A., Qu, H., Hughes, S. O., He, M., Wagner, S. E., Foushee, H. R., \& Shewchuk, R. M. (2011). Self-perceived lactose intolerance results in lower intakes of calcium and dairy foods and is associated with hypertension and diabetes in adults. The American Journal of Clinical Nutrition, 94(1), 191-198. https://doi.org/10.3945/ajcn.110.009860

Ntsame Affane, A. L., Muller, N., Van der Wijst, M., Sigge, G., \& Britz, T. J (2016). Metabolite profiles and acceptability by clusters of different kefir types for South African consumers. Journal of Microbiology, Biotechnology and Food Sciences, 05(04), 364-368. https://doi.org/10.15414/jmbfs.2016.5.4.364-368

Olfert ED, Cross BM, McWilliam AA. (1993). Laboratory animal care. In: Olfert ED, Cross BM, McWilliam AA, editors. Guide to the care and use of experimental animal. 2nd ed. Ottawa: Canadian Council on Animal Care. 82-93. https://ccac.ca/Documents/Standards/Guidelines/Experimental_Animals_Voll.pd $f$

Reid, R., Abramson, B. L., Blake, J., Desindes, S., Dodin, S., Johnston, S., Rowe, T., Sodhi, N., Penny Wilks, Wolfman, W., Fortier, M., Graves, L., Guthrie, B., Khan, A., Wilks, P., \& Soares, C. N. (2014). Managing Menopause. Journal of Obstetrics and Gynaecology Canada, 36(9), 830-833.h ttps://doi.org/10.1016/S1701-2163(15)30487-4

Roe, J. H. (1934). A colorimetric method for the determination of fructose in blood and urine. Journal of Biological Chemistry, 107(1), 15-22. https://doi.org/10.1016/s0021-9258(18)75382-9

Rosenfeld, D. L. (2018). The psychology of vegetarianism: Recent advances and future directions. In Appetite (Vol. 131, pp. 125-138). Academic Press. https://doi.org/10.1016/j.appet.2018.09.011

Shimizu, M. (2004). Food-derived peptides and intestinal functions. BioFactors, 21(1-4), 43-47. https://doi.org/10.1002/biof.552210109

Tiwari, P., Joshi, A., Varghese, E., \& Thakur, M. (2018). Process standardization and storability of calcium fortified potato chips through vacuum impregnation. Journal of Food Science and Technology, 55(8), 3221-3231. https://doi.org/10.1007/s13197-018-3254-3

Włodarek, D., Głaębska, D., Kołota, A., Adamczyk, P., Czekajło, A., Grzeszczak, W., Drozdzowska, B., \& Pluskiewicz, W. (2014). Calcium intake and osteoporosis: The influence of calcium intake from dairy products on hip bone mineral density and fracture incidence - A population-based study in women over 55 years of age.
Public
Health
Nutrition,
$17(2)$,
383-389.

https://doi.org/10.1017/S1368980012005307

Xiang, H., Sun-Waterhouse, D., Waterhouse, G. I. N., Cui, C., \& Ruan, Z. (2019).

Fermentation-enabled wellness foods: A fresh perspective. Food Science and Human Wellness, 8(3), 203-243. https://doi.org/10.1016/j.fshw.2019.08.003 